Revista Científica do Instituto Agronómico, Campinas

\title{
INFLUENCIA DO DIÂMETRO NA DENSIDADE BĀSICA DOS CAULES DE CROTALARIA JUNCEA E QUENAFE (HIBISCUS CANNABINUS) (1)
}

Anísio Azzini (2), Seção de Plantas Fibrosas, Léo Zimback, Indústria de Papel Pi. rahy, e Antonio Luiz de Barros Salgado (2), Seção de Plantas Fibrosas, Ins. tituto Agronômico.

\section{RESUMO}

Foram determinadas as densidades básicas dos caules de Crotalaria juncea e quenafe (Hibiscus cannabinus), utilizando-se os métodos do máximo teor de umidade (MTU) $e$ deslocamento da água (DA). Os resultados obtidos mostraram que houve uma relação direta entre os diâmetros dos caules e suas densidades básicas. Quanto aos métodos de determinaçăo, também houve diferenças significativas, sendo os maiores valores obtidos com o método do máximo teor de umidade.

\section{INTRODUÇÃO}

A densidade básica da matéria-prima vegetal para produção de celulose e papel é influenciada por diversos fatores, principalmente a espessura da parede celular das fibras, os elementos de vaso e as células parenquimatosas $(\mathbf{1}, \mathbf{2})$. Inúmeros trabalhos de pesquisa têm salientado que a densidade básica da matéria-prima fibrosa influi nas características físico-mecânicas do papel produzido e no rendimento de conversão em celulose. Desse modo, a densidade básica é importante característica do material fibroso a ser levada em consideração nos trabalhos de melhoramento genético, tendo em vista a uniformidade do produto final obtido.

A Crotalaria juncea é a principal matéria-prima fibrosa utilizada na manufatura de papel de cigarro, principalmente pelas características morfológicas de suas fibras, aliadas à sua combustibilidade lenta e inodora. O Estado de São Paulo é o maior produtor de fibras de crotalária, com uma produção aproximada de seis mil toneladas anuais. A cultura do quenafe (Hibiscus cannabinus), de menor expressão que a da crotalária,

(1) Recebido para publicação a 8 de agosto de 1981 .

(z) Com bolsa de suplementação do CNPq. 
vem nos últimos anos despertando grande interesse, visando à produção tanto de fibras têxteis como de celulose para papel.

O objetivo desse trabalho foi estudar a influência dos diâmetros na densidade básica dos caules de crotalaria e quenafe, bem como estabelecer um método de determinação a ser empregado em trabalhos de melhoramento genético.

\section{MATERIAL E MÉTODOS}

No presente estudo foram utilizadas 300 plantas de Crotalaria juncea e quenafe (Hibiscus cannabinus), provenientes do Centro Experimental de Campinas, do Instituto Agronômico. No laboratório, as plantas foram classificadas quanto aos diâmetros, em finas, médias e grossas.

A amostragem para a determinação da densidade básica foi feita na porção mediana de cada planta, retirando-se amostras com $10 \mathrm{~cm}$ de comprimento, que foram mantidas submersas em água, durante doze horas, para uma completa saturação. As determinações da densidade básica foram feitas em amostras com e sem líber (casca), empregando-se os seguintes métodos:

2.1 Método do deslocamento da água (DA)

$$
\mathrm{d}_{(\mathrm{DA})}=\frac{\text { Pas }}{\text { Vsa }}
$$

onde:

$$
\begin{aligned}
\mathrm{d}_{(\mathrm{DA})}= & \text { densidade básica da } \\
& \text { amostra, expressa em } \\
& \mathrm{g} / \mathrm{cm}^{3} ;
\end{aligned}
$$

$$
\begin{aligned}
\text { Pas }= & \text { peso da amostra seca } \\
& \text { em estufa a } 105 \pm 3^{\circ} \mathrm{C}, \\
& \text { até peso constante; } \\
\text { Vsa = } & \text { volume saturado da } \\
& \text { amostra, determinado } \\
& \text { pelo deslocamento da } \\
& \text { água em proveta gra- } \\
& \text { duada. }
\end{aligned}
$$

2.2 Método do máximo teor de umidade (MTU)

onde:

$$
\mathrm{d}_{(\mathrm{MTU})}=\frac{1}{\frac{\text { Pua }- \text { Psa }}{\text { Psa }}+\frac{1}{\mathrm{G}}}
$$

$$
\begin{aligned}
\mathrm{d}_{(\mathrm{MTU})}= & \text { densidade básica da } \\
& \text { amostra, expressa em } \\
\mathrm{g} / \mathrm{cm}^{3} ; & \\
\text { Pua }= & \text { peso ao ar da amostra } \\
& \text { saturada, após a re- } \\
& \text { moção em papel ab- } \\
& \text { sorvente da água } \\
& \text { superficial; } \\
\text { Psa }= & \text { peso da amostra seca } \\
& \text { em estufa a } 105 \pm \\
& 3^{\circ} \mathrm{C}, \text { até peso cons- } \\
& \text { tante; } \\
\mathrm{G}= & \text { densidade da subs- } \\
& \text { tância sólida da ma- } \\
& \text { deira. }
\end{aligned}
$$

Considerando que a densidade média da substância sólida da madeira seja $1,53 \mathrm{~g} / \mathrm{cm}^{3}(1)$, a expressão acima ficará:

$$
\mathrm{d}_{(\mathrm{MTU})}=\frac{1}{\frac{\text { Pua }}{\text { Psa }}-0,346}
$$

Além da densidade básica, determinaram-se também as densidades 
das substâncias sólidas dos caules de crotalária e quenafe pelo método do balão volumétrico, que representa uma variação do método do picnômetro, preconizado por STAMM (3), através da expressão:

$\mathrm{d}_{(\mathrm{s})}=\frac{\text { Psa }}{\text { PH }- \text { (Pua }+ \text { PH })- \text { Psa }}$

onde:

$$
\begin{aligned}
\mathrm{d}_{(\mathrm{s})}= & \text { densidade da subs- } \\
& \text { tância sólida, expres- } \\
& \text { sa em } \mathrm{g} / \mathrm{cm}^{3} ;
\end{aligned}
$$

Psa $=$ peso da amostra (serragem) seca em estufa a $105 \pm 3^{\circ} \mathrm{C}$, até peso constante;

$\mathrm{PH}=$ peso da água contida no balão;

Pua $=$ peso da amostra (serragem), completamente saturada.

\section{RESULTADOS E DISCUSSÃO}

Os valores médios dos diâmetros dos caules na região da amostragem foram $0,5,1,0$ e $1,4 \mathrm{~cm}$ para a crotalária e $0,6,1,2$ e $1,6 \mathrm{~cm}$ para o quenafe (Quadro 1).

Basicamente, os caules de crotalária e quenafe são constituídos por frações liberiana, lenhosa e medular. A fração medular, ao contrário das outras duas, não é fibrosa, tendendo a desaparecer quando a planta se torna adulta, principalmente no quenafe.

Nos quadros 2 e 3, pode-se observar que tanto os diâmetros dos caules como os métodos de determinação influíram significativamente no valor da densidade básica. As menores densidades foram obtidas nos caules com menores diâmetros, tanto para a crotalária como para o quenafe.

\begin{tabular}{|c|c|c|c|c|c|c|}
\hline \multirow{2}{*}{ Valores } & \multicolumn{3}{|c|}{ Crotalária } & \multicolumn{3}{|c|}{ Quenafe } \\
\hline & Fino & Médio & Grosso & Fino & Médio & Grosso \\
\hline & & $\mathrm{cm}$ & - & & $\mathrm{cm}-$ & سمب \\
\hline Máximo & 0,8 & 1,3 & 1,7 & 0,9 & 1,5 & 2,5 \\
\hline Médio & 0,5 & 1,0 & 1,4 & 0,6 & 1,2 & 1,6 \\
\hline Minimo & 0,3 & 0.9 & 1,2 & 0,4 & 1,0 & 1,2 \\
\hline $\mathbf{s}$ & 0,118 & 0,109 & 0,130 & 0,158 & 0,130 & 0,256 \\
\hline $\mathbf{s}(\mathbf{x})$ & 0,018 & 0,017 & 0,020 & 0,025 & 0,020 & 0,040 \\
\hline C.V. (\%) & 21,45 & 10,62 & 9,54 & 24,71 & 10,71 & 15,80 \\
\hline
\end{tabular}

QUADRO 1 - Diâmetro dos caules de Crotalaria juncea e quenafe (Hibiscus cannabinus) (Médias de quarenta repetiç̋es.)

$\mathbf{S}=$ desvio-padrāo; $\mathbf{S}(\mathbf{x})=$ erro-padrāo da médila; $\mathbf{C . V .}=$ coeficiente de variação. 
A fração liberiana (casca), que representa cerca de 23 e $40 \%$ (base seca) respectivamente dos caules de crotalária e quenafe, também influiu no valor da densidade básica. Os caules com casca ou líber apresentaram densidades mais elevadas.
Quanto aos métodos de determinação, a primeira preocupação foi com relação ao valor da densidade da substância madeira $\left(1,53 \mathrm{~g} / \mathrm{cm}^{3}\right)$ utilizado no método do máximo teor de umidade. Esse valor poderia estar superestimado para espécies nãoarbóreas, como crotalária e quenafe,

QUADRO 2 - Densidade básica dos caules de Crotalaria juncea em função do diâmetro e métodos de determinaçāo (Médias de 40 e 10 repetiçōes, respectivamente, para caules com e sem casca)

\begin{tabular}{|c|c|c|c|c|c|c|}
\hline \multirow{2}{*}{ Métodos } & \multicolumn{3}{|c|}{ Caules com casca } & \multicolumn{3}{|c|}{ Caules sem casca } \\
\hline & Fino & Médio & Grosso & Fino & Médio & Grosso \\
\hline & & $\mathrm{g} / \mathrm{cm}^{3}$ & & & $\mathrm{~g} / \mathrm{cm}^{\mathrm{t}}$ & \\
\hline DA & 0,157 & 0,225 & 0,254 & 0,134 & 0,219 & 0,266 \\
\hline MTU & 0,248 & 0,308 & 0,298 & 0,256 & 0,327 & 0,366 \\
\hline
\end{tabular}

Teste $\mathbf{F}$

Diâmetro

$53,76^{* * *}$

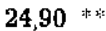

Métodos

$416,33 * *$

$991,10^{* *}$

DA = Método do deslocamento de água; MTU = Método do máximo teor de umidade. ** = Significativo ao nivel de $1 \%$.

QUADRO 3 - Densidade básica dos caules de quenafe (Hibiscus cannabinus) em funçāo do diâmetro e método de determinação (Médias de 40 e 10 repetiçōes, respectivamente, para caules com e sem casca)

\begin{tabular}{|c|c|c|c|c|c|c|}
\hline \multirow{2}{*}{ Métodos } & \multicolumn{3}{|c|}{ Caules com casca } & \multicolumn{3}{|c|}{ Caules sem casca } \\
\hline & Fino & Médio & Grosso & Fino & Médio & Grosso \\
\hline & & $\mathrm{g} / \mathrm{cm}^{3}$ & $\ldots$ & 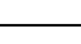 & $-\mathrm{g} / \mathrm{cm}^{3}$ & - \\
\hline DA & 0,115 & 0,156 & 0,181 & 0,087 & 0,132 & 0,170 \\
\hline MTU & 0,170 & 0,199 & 0,219 & 0,151 & 0,186 & 0,209 \\
\hline
\end{tabular}

Teste $\mathbf{F}$

Diâmetro

Método

$\mathbf{D A}=$ Método do deslocamento de água; $\mathrm{MTU}=$ Método do máximo teor de umidade. ** = Significativo ao nivel de $1 \%$. 
com crescimento bastante rápido. Os dados do quadro 4 mostram que os valores das densidades das substâncias sólidas dos caules de crotalária e quenafe são semelhantes aos das madeiras.

A menor densidade obtida com o método do deslocamento de água deve estar relacionada com a presença da fração medular, que superestima o volume da amostra considerada. Para o quenafe, a fração medular na região amostrada representa cerca de $20 \%$ do diâmetro do caule.

\section{CONCLUSÓES}

a) As densidades básicas dos caules de Crotalaria juncea e quenafe (Hibiscus cannabinus) variaram com os diâmetros: os caules mais grossos apresentaram densidades mais elevadas. b) A fração medular nos caules de crotalária e quenafe é bastante desenvolvida e tende a desaparecer com o desenvolvimento da planta, ficando em seu lugar um vazio ou oco.

c) A fração medular deve influir na determinação da densidade básica dos caules de crotalária e quenafe, principalmente no método do deslocamento da água, onde o volume da amostra é superestimado.

d) Os caules de crotalária foram mais densos que os do quenafe, provavelmente devido à menor quantidade da fração medular.

e) A densidade da substância sólida dos caules de crotalária e quenafe é semelhante à da madeira.

f) Como houve diferenças significativas entre os métodos na determinação da densidade básica, há necessidade de novos estudos para definir o método mais adequado.

QUADRO 4 - Densidade da substancia sólida dos caules de Crotalaria juncea e quenafe (Hibiscus cannabinus) (Médias de sete repetiçōes )

\begin{tabular}{|c|c|c|c|c|c|}
\hline \multirow{2}{*}{ Valores } & \multicolumn{2}{|c|}{ Crotalária } & & \multicolumn{2}{|c|}{ Quenafe } \\
\hline & Liber & Lenho & & Liber & Lenho \\
\hline & & & $\mathrm{g} / \mathrm{cm}^{\mathrm{x}}$ & & \\
\hline Máximo & 1,517 & 1,552 & & 1,544 & 1,551 \\
\hline Médio & 1,435 & 1,495 & & 1,395 & 1,492 \\
\hline Mínimo & 1,327 & 1,440 & & 1,291 & 1,354 \\
\hline $\mathbf{S}$ & 0,084 & 0,050 & & 0,108 & 0,078 \\
\hline $\mathbf{S}(\mathrm{x})$ & 0,032 & 0,019 & & 0,041 & 0,029 \\
\hline C.v. (\%) & 5,935 & 3,393 & & 7,816 & 5,254 \\
\hline
\end{tabular}

$\mathbf{S}=$ desvio-padrão; $\mathbf{S}(\mathrm{x})=$ erro-padräo da média; $\mathrm{C.V} .=$ coeficiente de variação. 


\section{INFLUENCE OF THE DIAMETER ON THE BASIC DENSITY OF SUNN HEMP AND KENAF STALKS}

\section{SUMMARY}

The basic density of sunn hemp (Crotalaria juncea) and Kenaf (Hibiscus cannabinus) stalks were determined by the Maximum Moisture Content Method and Water Displacement Method. The density of the solid substance of sunn hemp and Kena? stalks was also determined.

The results showed a direct relationship between diameter of the stalks and basic density. The density of the solid substance of sunn hemp and Kenaf stalks was similar to the density of wood substance.

\section{REFERENCIAS BIBLIOGRAFICAS}

1. FOELKEL, C. E. B.; BRASIL, M. A. M.; BARRICHELO, L. E. G. Métodos para determinação da densidade básica de cavacos para confferas e folhosas. IPEF, Piracicaba, 2/3:65-74, 1971.

2. SCARAMUZZI, G. A comparison of some methods for determining the basic density of increment cores of Euramerican poplar hybrids. In: WORLD FORESTRY CONGRESS, 6., Madrid, 1966. Proceedings. v.3. p.3454-3459.

3. STAMM, A. J. Wood and cellulose science. New York, Ronald Press, 1964. 549p. 